\title{
Molecular biology of colorectal cancer: Review of the literature
}

\author{
Elrasheid A. H. Kheirelseid, Nicola Miller, Michael J. Kerin
}

Department of Surgery, National University of Ireland, Galway, Ireland

Email: rashmed1111@gmail.com

Received 10 February 2013; revised 26 March 2013; accepted 20 April 2013

Copyright (c) 2013 Elrasheid A. H. Kheirelseid et al. This is an open access article distributed under the Creative Commons Attribution License, which permits unrestricted use, distribution, and reproduction in any medium, provided the original work is properly cited.

\begin{abstract}
Colorectal cancer (CRC) results from the progressive accumulation of genetic and epigenetic alterations that lead to the transformation of normal colonic epithelium to colon adenocarcinoma. From the analysis of the molecular genesis of colon cancer, four central tenets concerning the pathogenesis of cancer have been established. The first is that the genetic and epigenetic alterations that underlie colon cancer formation promote the cancer formation process because they provide a clonal growth advantage to the cells that acquire them. The second tenet is that cancer emerges via a multi-step progression at both the molecular and the morphologic level. The third is that loss of genomic stability is a key molecular step in cancer formation. The fourth is that hereditary cancer syndromes frequently correspond to germ line forms of key genetic defects whose somatic occurrences drive the emergence of sporadic colon cancers.
\end{abstract}

Keywords: Genetics of Colorectal Cancer; Molecular Biology of Colorectal Cancer; Colorectal Cancer

\section{INTRODUCTION}

Oncogene and tumour-suppressor gene mutations all operate similarly at the physiological level: they drive the neoplastic process by increasing tumour cell number through the stimulation of cell birth or the inhibition of cell death or cell-cycle arrest. The increase can be caused by activating genes that drive the cell cycle, by inhibiting normal apoptotic processes or by facilitating the provision of nutrients through enhanced angiogenesis. A third class of cancer genes, called stability genes, promotes tumourigenesis in a completely different way when mutated. This class includes the mismatch repair (MMR), nucleotide-excision repair (NER) and base-excision re- pair (BER) genes responsible for repairing subtle mistakes made during normal DNA replication or induced by exposure to mutagens. Other stability genes control processes involving large portions of chromosomes, such as those responsible for mitotic recombination and chromosomal segregation (e.g., BRCA1, BLM and $A T M$ ). Stability genes keep genetic alterations to a minimum, and thus when they are inactivated, mutations in other genes occur at a higher rate [1]. All genes are potentially affected by the resultant increased rate of mutation, but only mutations in oncogenes and tumour-suppressor genes affect net cell growth and can thereby confer a selective growth advantage to the mutant cell. As with tumour-suppressor genes, both alleles of stability genes generally must be inactivated for a physiologic effect to result.

Mutations in these three classes of genes can occur in the germline, resulting in hereditary predispositions to cancer, or in single somatic cells, resulting in sporadic tumours. It is important to point out that a mutation is defined as any change in the sequence of the genome. These changes include those affecting single base pairs as well as those creating large or small deletions or insertions, amplifications or translocations. In the germline, the most common mutations are subtle (point mutations or small deletions or insertions), whereas all types of mutation can be found in tumour cells. In fact, cancers represent one of the few disease types in which somatic mutations occurring after birth are pathogenic. The first somatic mutation in an oncogene or tumour-suppressor gene that causes a clonal expansion initiates the neoplastic process [2]. Subsequent somatic mutations result in additional rounds of clonal expansion and thus in tumour progression [3]. Germline mutations of these genes cause cancer predisposition, not cancer per se. Such individuals therefore often develop multiple tumours that occur at an earlier age than in individuals whose cancergene mutations have all occurred somatically [4]. 


\section{GENETICS AND EPIGENETICS ALTERATIONS IN CRC}

Colorectal cancer results from the progressive accumulation of genetic and epigenetic alterations that lead to the transformation of normal colonic epithelium to colon adenocarcinoma. From the analysis of the molecular genesis of colon cancer, four central tenets concerning the pathogenesis of cancer have been established. The first is that the genetic and epigenetic alterations that underlie colon cancer formation promote the cancer formation process because they provide a clonal growth advantage to the cells that acquire them. The second tenet is that cancer emerges via a multi-step progression at both the molecular and the morphologic levels [5]. The third is that loss of genomic stability is a key molecular step in cancer formation [6]. The fourth is that hereditary cancer syndromes frequently correspond to germ line forms of key genetic defects whose somatic occurrences drive the emergence of sporadic colon cancers [7]

\subsection{Genetic Alterations}

Much progress has been made in understanding the molecular mechanism of CRC since 1990, when Fearon and Vogelstein proposed their genetic model for CRC tumourigenesis [5]. A progression from normal mucosa to adenoma to carcinoma was supported by the demonstration of accumulating mutations in genes of $A P C$, $K-R A S, P 53$ and DCC, all of which are thought to be of significance, but are not able successfully to account for all CRCs. The earliest identifiable lesion in colon-cancer formation is the aberrant crypt focus (ACF). The true neoplastic potential of this lesion is still undetermined, but it does appear that some of these lesions can progress to frank adenocarcinoma and harbor mutations in $K-R A S$ or $A P C$. In particular, dysplastic aberrant crypt foci frequently carry mutations in $A P C$ and appear to have the highest potential for progressing to colon cancer. Thus, alterations in $A P C$, which result in overactivation of the Wingless/Wnt signalling pathway, appear to initiate tumour formation in the colon. Subsequent alterations in other genes then play a role in tumour growth and the eventual acquisition of other malignant characteristics such as tissue invasiveness and the ability to metastasize.

\subsubsection{APC}

The Adenomatous polyposis coli (APC) gene encodes a protein that possesses multiple functional domains that mediate oligomerization as well as binding to a variety of intracellular proteins including $\beta$-catenin, $\gamma$-catenin, glycogen synthase kinase (GSK)-3 $\beta$, axin, tubulin, EB1, and hDLG [7]. Germline mutations in $A P C$ result in FAP or one of its variants, Gardner's syndrome, attenuated FAP, Turcott's syndrome, or the flat adenoma syndrome
[8,9]. In addition; studies have shown that $A P C$ is mutated in up to $70 \%$ of all sporadic colon adenocarcinomas, which is a high $A P C$ mutation frequency unique to colorectal cancers $[10,11]$. These mutations are present beginning in the earliest stages of colon-cancer formation and precede the other alterations observed during coloncancer formation $[12,13]$. One of the central tumourpromoting effects of these mutations results in overactivation of the Wingless/Wnt signalling pathway, with the subsequent expression of genes that favor cell growth. $A P C$ mutations disrupt the association of $A P C$ with $\beta$ catenin, resulting in excessive amounts of $\beta$-catenin and overactivation of the Wnt signalling pathway. Consequently, genes that promote tumour formation are transcribed. The over-activation of the Wnt signalling pathway occurs because normally GSK- $3 \beta$ forms a complex with $A P C, \beta$-catenin, and axin and phosphorylates these proteins. The phosphorylation of $\beta$-catenin targets it for ubiquitin-mediated proteasomal degradation. Truncating $A P C$ mutations prevent this process from happening and cause an increase in the amount of cytoplasmic $\beta$-catenin, which can then translocate to the nucleus and interact with other transcription factors.

\subsubsection{K-RAS}

Kirstein rat sarcoma $(K-R A S)$ is a member of the RAS family of genes and present one of the most prominent proto-oncogenes in colon carcinogenesis. The RAS family genes encode highly conserved proteins that are involved in signal transduction. One major function of the RAS protein family is to couple growth factors to the Raf-mitogen-activated protein (MAP) kinase kinaseMAP kinase signal transduction pathway, which leads to the nuclear expression of early response genes [14]. $K-R A S$ mutations have been found in $37 \%-41 \%$ of colon carcinomas and appear to occur relatively early in colon-cancer formation [15,16]. Vogelstein et al. [13] found $K-R A S$ mutations in $13 \%$ of small tubular adenomas, $42 \%$ of large adenomas, and $57 \%$ of adenomas that contained areas of invasive carcinoma. In fact, 58\% of adenomas greater than $1 \mathrm{~cm}$ in size had RAS mutations, compared to $9 \%$ of adenomas less than $1 \mathrm{~cm}$ in size [13]. These results have been supported by other investigators who have found an incidence of approximately $40 \%$ in colon adenomas [15]. The $K-R A S$ mutations appear to follow $A P C$ mutations and are associated with advanced adenomatous lesions. Evidence for this model comes from the observation that small adenomas with $A P C$ mutations carry $K-R A S$ mutations in approximately $20 \%$ of the tumours, whereas approximately $50 \%$ of more advanced adenomas have $K-R A S$ mutations $[12,17]$. Thus, alterations of $K-R A S$ appear to promote colon-cancer formation early in the adenoma-carcinoma sequence by mediating adenoma growth. Of interest, 
however, they do not appear necessary for the malignant conversion of adenomas to adenocarcinomas.

\subsection{3. $P 53$}

Tumour protein-53 ( $P 53)$ was initially identified as a protein forming a stable complex with the SV40 large T antigen and was originally suspected to be an oncogene [18]. Subsequent studies demonstrated that $P 53$ is a transcription factor with tumour suppressor activity, is located at chromosome $17 \mathrm{p} 13.1$, and is mutated in $50 \%$ of primary human tumours, including tumours of the gastrointestinal tract [19]. $P 53$ is currently believed to be a transcription factor that is involved in maintaining genomic stability through the control of cell cycle progression and apoptosis in response to genotoxic stress [19]. In colon cancers, $P 53$ mutations have not been observed in colon adenomas, but rather appear to be late events in the colon adenoma-carcinoma sequence that may mediate the transition from adenoma to carcinoma [13]. Furthermore, mutation of $P 53$ coupled with loss of heterozygosity $(\mathrm{LOH})$ of the wild-type allele was found to coincide with the appearance of carcinoma in an adenoma, thus providing further evidence of its role in the transition to malignancy [20,21]. The function of $P 53$ to recognize DNA damage and induce cell cycle arrest and DNA repair or apoptosis has led to $P 53$ being called the "guardian of the genome" [22]. Thus, P53 normally acts as a tumour suppressor gene by inducing genes that can cause cell cycle arrest or apoptosis and also by inhibiting angiogenesis through the induction of TSP1 [23]. Mutant $P 53$ can block these functions by forming oligomers with wild-type TP53, thereby causing diminished DNA-binding specificity [24].

\subsubsection{DCC}

Since it was first discovered in a colorectal cancer study in 1990 [25], DCC (Deleted in colorectal cancer) has been the focus of a significant amount of research. DCC held a controversial place as a tumour suppressor gene for many years, and is well known as an axon guidance receptor that responds to netrin-1 [26]. More recently DCC has been characterized as a dependence receptor, and theories have been put forward that have revived interest in DCC's candidacy as a tumour suppressor gene, as it may be a ligand-dependent suppressor that is frequently epigenetically silenced. One of the most frequent genetic abnormalities that occur in advanced colorectal cancer is loss of heterozygosity (LOH) of DCC in region 18q21. DCC elimination is not believed to be a key genetic change in tumour formation, but one of many alterations that can promote existing tumour growth.

\subsection{Epigenetic Alterations}

The finding of aberrant $h M L H 1$ promoter methylation in sporadic MSI colon cancers dramatically illustrated the role of epigenetic changes as potential pathogenetic alterations in cancer [27-30]. The term DNA methylation refers to the methylation of cytosine residues (5-methy lcytosine) at $\mathrm{CpG}$ sites found throughout the genome [31]. These epigenetic alterations are characteristically clustered in so-called $\mathrm{CpG}$ islands in gene promoter regions, and hypo and hypermethylation of these regions are related to activation and inhibition of transcription, respectively. This type of gene regulation is essential to cell differentiation as well as embryological development [32]. Furthermore, DNA methylation is closely related to the mechanism by which one copy of a gene is preferentially silenced according to parental origin, generally referred to as genomic imprinting [33]. Aber rantmethylation of the cancer genome, and associated silencing of the genes whose promoters demonstrated such methylation, has been well described at multiple genetic loci $[34,35]$. Reversion of the methylation using demethylating agents such as 5-deoxy-azacytidine frequently restores expression of these genes, demonstrating methylation in fact induces gene silencing. As inactivation of $h M L H 1$ plays an initiating role in the pathogenesis of MSI colon cancers, the finding of aberrant methylation of $h M L H 1$ in sporadic MSI colon cancers, and the restoration of $h M L H 1$ expression by demethylating the $h M L H 1$ promoter in cell lines derived from such cancers, strongly suggests that such aberrant methylation could be a cause rather than a consequence of colon carcinogenesis [28-30]. Moreover, Grady et al. [36] provided additional evidence for the primary role of aberrant methylation in gastrointestinal carcinogenesis. They demonstrated that, loss of expression of E-cadherin (CDH1) in association with CpG methylation of the wild-type $C D H 1$ allele in tumours occurs in the setting of the cancer family syndrome Hereditary Diffuse Gastric Cancer. Epigenetic and genetic changes also appear to cooperate to promote cancer formation [37]. Moreover, the aberrant hypermethylation of $50 \mathrm{CpG}$ dinucleotides that has been demonstrated to silence a variety of tumour suppressor genes including $C D H 1, C D K N 2 A / p 16, T S P 1$, and GSTP1 may be similarly pathogenic in the tumours in which these changes have been identified [28,37-40].

\section{GENETIC CLASSIFICATION OF CRC}

Colorectal carcinoma (CRC) is generally classified into three categories, based on increasing hereditary influence and cancer risk [41]. Sporadic CRC (60\%) comprises patients with no notable family history and, by definition, with no identifiable inherited gene mutation that accelerates cancer development. Familial CRC (30\%) refers to patients who have at least one blood relative with CRC or an adenoma, but with no specific germline mutation or clear pattern of inheritance. Hereditary CRC 
syndromes (10\%) which result from germline inheritance of mutations in highly penetrant cancer susceptibility genes. Although the last group is observed with the lowest frequency, however they have been instrumental in the elucidation of molecular mechanisms of carcinogenesis applicable to sporadic CRC.

\subsection{Sporadic CRC}

Sporadic colorectal cancers arise at a median age of 70 75 years. Seventy percent arise in the left side of the colon and there are differences in the age, sex and regional distribution of both adenomas and carcinomas between both sides of the large bowel. Sporadic cancers caused by the development of a series of genetic abnormalities in tumour suppressor genes and oncogenes that give cells an evolutionary advantage over their neighbours.

\subsection{Hereditary and Familial CRC Syndromes}

\subsubsection{Hereditary Non-Polyposis Colorectal Cancer (Lynch Syndrome)}

Hereditary non-polyposis colorectal cancer, also referred to as the Lynch syndrome, is the most common form of hereditary colorectal cancer. It is inherited in an autosomal dominant fashion its clinical consequences develop from germline mutations in mismatch repair (MMR) genes. The lack of functional MMR proteins leads to genomic instability and development of various cancers. Multiple generations are affected with colorectal cancer at an early age (mean, approximately 45 years) with a predominance of right-sided colorectal cancer (approximately 70 percent proximal to the splenic flexure). There is an excess of synchronous colorectal and metachronous colorectal cancer. In addition, there is an excess of extracolonic cancers, namely, carcinoma of the endometrium, ovary, stomach, small bowel, pancreas, hepatobiliary tract, brain, and upper uroepithelial tract $[42,43]$ As compared with sporadic colorectal cancer, tumours in hereditary non-polyposis colorectal cancer are more often poorly differentiated, with an excess of mucoid and signet-cell features, a Crohn's-like reaction, and the presence of infiltrating lymphocytes within the tumour [4446].

\subsubsection{Familial Adenomatous Polyposis}

Familial adenomatous polyposis (FAP) is characterized by numerous ( $>100$, usually several hundreds in fully developed cases) of adenomatous colorectal polyps. In general, less than $1 \%$ of all new CRC arise in FAP patients. FAP is an autosomal dominant hereditary cancer syndrome caused by a germline mutation in the $A P C$ gene (adenomatous polyposis coli). Because this syndrome may be associated fewer number of colonic polyps ("attenuated" FAP), it may first present with extra-intestinal manifestations and because as many as $50 \%$ of FAP patients result from new germline mutations in $A P C$ gene, pathologists may be the first to suspect this hereditary condition. Gardner syndrome is characterized by epidermoid cysts, osteomas, dental anomalies and desmoid tumours (fibromatoses). Turcot syndrome is an association between colorectal polyposis and primary central nervous system (CNS) tumour (usually medulloblastomas) [47,48]. Extra-gastrointestinal manifestations may be of importance for practicing pathologists in diagnosis of unsuspected FAP. Desmoid tumour (fibromatosis) is rare in the general population, but it is commonly seen in FAP and it may be the first manifestation of disease. Patients with FAP typically develop in retroperitoneal tissues or in the abdominal wall following surgical trauma (abdominal desmoids), while fibromatoses unrelated to FAP are more common in extra-abdominal localizations [49]. Papillary carcinoma of the thyroid and its rare cribriform-morular variant may be associated with FAP, and this could lead to detection of unsuspected FAP [50,51]. The risk of hepatoblastoma in children of patients with FAP is highly increased and new germline mutations can be identified in $10 \%$ of cases [52].

\subsubsection{Hamartomatous Polyposes Syndromes}

The hamartomatous polyposis syndromes include PeutzJeghers syndrome, juvenile polyposis, Cronkhite-Canada, and Cowden disease/Bannayan-Riley-Ruvalcaba syndrome [53-55]. Hamartomatous polyposes syndromes are distinguished by their characteristic clinicopathologic and radiologic features.

All of these syndromes are characterized by hamartomatous polyps and most of them are associated with increased risk of development of gastrointestinal and extraintestinal carcinomas [56].

1) Peutz-Jeghers Syndrome (PJS):

Peutz-Jeghers syndrome (PJS) is characterized by mucocutanous pigmentation and GI hamartomas, which occur anywhere from stomach to anus. It was first described by Peutz in 1921 [57] and Jeghers in 1944 [58]. It is inherited in an autosomal dominant fashion with no sex predilection [59]. A prototypic PJS polyp is a hamartoma of the muscularis mucosae. Therefore, the core of the polyp consists of smooth muscle covered by lamina propria and mature glandular epithelium [60,61] which gives rise to a characteristic arborising smooth muscle core of the polyp. Germ-line mutations in the serine/threonine kinase gene (STK11/LKB1) on chromosome 19p13.3 cause Peutz-Jeghers syndrome in about half of the affected families. Additional loss of the wildtype allele in hamartomas and adenocarcinomas suggests that STK11/LKB1 is a tumour suppressor gene [62].

2) Juvenile polyposis coli (JP):

Juvenile polyposis (JP) coli is inherited in an auto- 
somal dominant fashion at least in $30 \%$ of patients. Patients develop numerous hamartomatous colorectal polyps, which are characterized by dilated crypts [63]. The number of polyps is smaller than in FAP and the disease course is less malignant [64]. The diagnosis of juvenile polyposis syndrome is made when multiple (3 - 10) juvenile polyps are found in the gastrointestinal tract, even though there is still some variation in criteria used in diagnosis. Mutations of SMAD4/MADH4 gene were initially described and explain about $30 \%$ of cases [65]. Mutations in BMPR1A can also lead to juvenile polyposis in additional $30 \%$ of patients $[66,67]$.

\section{GENETIC INSTABILITY OF CRC}

Colorectal cancer is a heterogeneous disease that can develop through different genetic pathways. The most common is termed the chromosomal instability pathway and accounts for $70 \%$ to $85 \%$ of colorectal cancers (13). These tumours are characterized by mutations in $A P C$, $P 53$, and $K R A S$ and by frequent allelic loss at 18q [68]. Aneuploidy, amplifications, and translocations are also common in these tumours. Familial adenomatous polyposis is the hereditary syndrome associated with these changes [46]. The microsatellite instability (MSI) pathway, comprising the remaining $15 \%$ of colorectal cancers, is characterized by loss of proficiency of the DNA mismatch repair (MMR) system and MSI.

\section{Microsatellite Instability (MSI)}

Microsatellites are repeated DNA sequences, usually 1 to 10 nucleotides long, present throughout the genome. Instability is mostly characterized by single base-pair insertions or deletions in these repeat loci, causing widespread genomic instability due to the failure of the cell's mismatch repair (MMR) mechanism. MSI occurs as a consequence of inactivation of the mutation mismatch repair system and is recognized by frame shift mutations in microsatellite repeats located throughout the genome. Inactivation of the MMR system due to germ line gene defects accounts for the colon cancer family syndrome, hereditary non-polyposis colon cancer syndrome (HNPCC). Somatic inactivation of the mismatch repair system additionally gives rise to approximately $15 \%$ of sporadic colon cancers. In either instance the resulting colon cancers display the phenotype of microsatellite instability. The demonstration of microsatellite unstable cancers is generally performed by assaying for alterations at microsatellite loci that are particularly frequently mutated in the setting of MMR inactivation. Since many colon cancers demonstrate frame shift mutations at a small percentage of microsatellite repeats, the designation of a colon tumour as showing microsatellite instability depends on the detection of at least two unstable loci out of five from a panel of loci that were selected by a National Cancer Institute consensus conference [69].

Genes that possess such microsatellite-like repeats in their coding regions appear to be the targets relevant to carcinogenesis. Indeed, frequently, many genes that possess microsatellite repeats are observed to be mutated in MSI colon cancers. The relationship between the microsatellite mutator pathway and other genetic alterations frequently found in colon cancer is only partially understood. Alteration of the Wnt/Wingless pathway can be observed in tumours irrespective of MSI [70]. Mutations in $A P C$ and $C T N N B 1$ can be found in $21 \%$ and $43 \%$ of MSI tumours, respectively [71,72]. In addition, the incidence of $K-R A S$ mutations appears to be as high as $22 \%-31 \%$, which is similar to the incidence observed in microsatellite stable (MSS) colon cancers [73]. Mutations in $P 53$ do appear to be less frequent in MSI cancers than in MSS cancers. The mutation incidence in MSI colon cancers has been demonstrated to range between $0 \%-40 \%$, whereas the incidence in MSS tumours is between 31\% - 67\% [71,73,74].

The MSI tumour formation process has been termed the microsatellite mutator phenotype and is a pathway to tumour formation that is distinct from that seen in colon cancers that are microsatellite stable [75-77]. The most frequently targeted gene for mutation in this pathway is the TGF- $\beta$ receptor type II tumour suppressor gene (TGFBR2). Other less frequently targeted genes include the ACVR2, BAX, RIZ, CDX2, SEC63, AIM2, MSH3 and MSH6 [77-80]. CTNNB1 mutations are also found in $25 \%$ of MSI colon cancers but are not found in MSS cancers.

The Lynch syndrome is caused mainly by germ-line mutations in the DNA mismatch repair genes and heterozygosity for a mutation results in susceptibility to the cancer. Lynch syndrome can be identified based on age at onset, previous medical history and the characteristics of family history that fulfil the Amsterdam criteria and Bethesda guidelines for the diagnosis of hereditary nonpolyposis colorectal cancer (HNPCC) [81-84]. The early recognition of Lynch syndrome is essential to identify patients at high risk who will require intensive surveillance. Nevertheless; its diagnosis can be difficult to make due to incomplete family history information and lake of characteristic clinical phenotype. Although the Amsterdam criteria and Bethesda guidelines continue to be used widely, several studies have underscored the limitations of their accuracy in predicting the presence of MMR gene mutations $[85,86]$. Therefore, new strategies for screening for and diagnosis of Lynch syndrome need to be investigated.

In addition to screening for Lynch syndrome, testing for MSI is important because of its possible prognostic and therapeutic implications. Cancers with high mi- 
crosatellite instability (H-MSI) were reported to have a more favourable clinical outcome than non-MSI tumours and the survival advantage conferred by the MSI phenotype is independent of tumour stage and other clinicopathological variables [87-89]. Moreover, tumours with $\mathrm{H}-$ MSI are thought to be less responsive to 5-fluorouracil and other anticancer agents in vitro and in vivo [90-92].

\section{ACKNOWLEDGEMENTS}

The authors would like to acknowledge the National Breast Cancer Research Institute (NBCRI) their funding of this study.

\section{REFERENCES}

[1] Friedberg, E.C. (2003) DNA damage and repair. Nature, 421, 436-440. doi:10.1038/nature01408

[2] Nowell, P.C. (2002) Tumor progression: A brief historical perspective. Seminars in Cancer Biology, 12, 261-266. doi:10.1016/S1044-579X(02)00012-3

[3] Maley, C.C., Galipeau, P.C., Li, X.H., et al. (2004) Selectively advantageous mutations and hitchhikers in neoplasms: p16 lesions are selected in Barrett's esophagus. Cancer Research, 64, 3414-3427. doi:10.1158/0008-5472.CAN-03-3249

[4] Knudson, A.G. (2002) Cancer genetics. American Journal of Medical Genetics, 111, 96-102. doi:10.1002/ajmg.10320

[5] Fearon, E.R. and Vogelstein, B. (1990) A genetic model for colorectal tumorigenesis. Cell, 61, 759-767. doi:10.1016/0092-8674(90)90186-I

[6] Lengauer, C., Kinzler, K.W. and Vogelstein, B. (1998) Genetic instabilities in human cancers. Nature, 396, 643649. doi:10.1038/25292

[7] Vogelstein, B. and Kinzler, K.W. (1996) Lessons from hereditary colorectal cancer. Cell, 87, 159-170. doi:10.1016/S0092-8674(00)81333-1

[8] Foulkes, W.D. (1995) A tale of four syndromes: Familial adenomatous polyposis, Gardner syndrome, attenuated APC and Turcot syndrome. Monthly Journal of the Association of Physicians, 88, 853-863.

[9] Soravia, C., Berk, T., Madlensky, L., et al. (1998) Genotype-phenotype correlations in attenuated adenomatous polyposis coli. American Journal of Human Genetics, 62, 1290-1301. doi:10.1086/301883

[10] Miyaki, M., Konishi, M., Kikuchiyanoshita, R., et al. (1994) Characteristics of somatic mutation of the adenomatous polyposis-coli gene in colorectal tumors. Cancer Research, 54, 3011-3020.

[11] Chung, D.C. (2000) The genetic basis of colorectal cancer: Insights into critical pathways of tumorigenesis. Gastroenterology, 119, 854-865. doi:10.1053/gast.2000.16507

[12] Powell, S.M., Zilz, N., Beazer-Barclay, Y., et al. (1992) $A P C$ mutations occur early during colorectal tumorigenesis. Nature, 359, 235-237. doi:10.1038/359235a0

[13] Vogelstein, B., Fearon, E.R., Hamilton, S.R., et al. (1988)
Genetic alterations during colorectal-tumor development. New England Journal of Medicine, 319, 525-532. doi:10.1056/NEJM198809013190901

[14] Bokoch, G.M. and Der, C.J. (1993) Emerging concepts in the ras superfamily of Gtp-binding proteins. FASEB Journal, 7, 750-759

[15] Arber, N., Shapira, I., Ratan, J., et al. (2000) Activation of c-K-ras mutations in human gastrointestinal tumors. Gastroenterology, 118, 1045-1050. doi:10.1016/S0016-5085(00)70357-X

[16] Bos, J.L., Fearon, E.R., Hamilton, S.R., et al. (1987) Prevalence of ras gene-mutations in human colorectal cancers. Nature, 327, 293-297. doi:10.1038/327293a0

[17] Tsao, J.I. and Shibata, D. (1994) Further evidence that one of the earliest alterations in colorectal carcinogenesis involves APC. American Journal of Pathology, 145, 531534.

[18] Ochiai, A. and Hirohashi, S. (1997) Multiple genetic alterations in gastric cancer. Oxford University Press, New York.

[19] Somasundaram, K. and El-Deiry, W.S. (2000) Tumor suppressor P53: Regulation and function. Frontiers in Bioscience, 5, D424-D437. doi:10.2741/Somasund

[20] Ohue, M., Tomita, N., Monden, T., et al. (1994) A frequent alteration of $P 53$ gene in carcinoma in adenoma of colon. Cancer Research, 54, 4798-4804.

[21] Kikuchiyanoshita, R., Konishi, M., Ito, S., et al. (1992) Genetic changes of both $P 53$ alleles associated with the conversion from colorectal adenoma to early carcinoma in familial adenomatous polyposis and nonfamilial adenomatous polyposis patients. Cancer Research, 52, 39653971.

[22] Lane, D.P. (1993) Cancer-A death in the life of $P 53$. Nature, 362, 786-787. doi:10.1038/362786a0

[23] Levine, A.J. (1997) P53, the cellular gatekeeper for growth and division. Cell, 88, 323-331 doi:10.1016/S0092-8674(00)81871-1

[24] Howe, J.R. and Guillem, J.G. (1997) The genetics of colorectal cancer. Surgical Clinics of North America, 77, 175-195. doi:10.1016/S0039-6109(05)70538-7

[25] Fearon, E.R., Cho, K.R., Nigro, J.M., et al. (1990) Identification of a chromosome-18q gene that is altered in colorectal cancers. Science, 247, 49-56. doi:10.1126/science.2294591

[26] Bernet, A. and Mehlen, P. (2007) Dependence receptors: When apoptosis controls tumor progression. Bull Cancer, 98, E12-E17.

[27] Breivik, J. and Gaudernack, G. (1999) Genomic instability, DNA methylation, and natural selection in colorectal carcinogenesis. Seminars in Cancer Biology, 9, 245-254. doi:10.1006/scbi.1999.0123

[28] Herman, J.G., Umar, A., Polyak, K., et al. (1998) Incidence and functional consequences of $h M L H 1$ promoter hypermethylation in colorectal carcinoma. Proceedings of the National Academy of Sciences of the United States of America, 95, 6870-6875. doi:10.1073/pnas.95.12.6870

[29] Kane, M.F., Loda, M., Gaida, G.M., et al. (1997) Methy- 
lation of the $h M L H 1$ promoter correlates with lack of expression of $h M L H 1$ in sporadic colon tumors and mismatch repair-defective human tumor cell lines. Cancer Research, 57, 808-811.

[30] Veigl, M.L., Kasturi, L., Olechnowicz, J., et al. (1998) Biallelic inactivation of $h M L H 1$ by epigenetic gene silencing, a novel mechanism causing human MSI cancers. Proceedings of the National Academy of Sciences of the United States of America, 95, 8698-8702. doi:10.1073/pnas.95.15.8698

[31] Ramsahoye, B.H., Davies, C.S. and Mills, K.I. (1996) DNA methylation: Biology and significance. Blood Reviews, 10, 249-261. doi:10.1016/S0268-960X(96)90009-0

[32] Monk, M. (1995) Epigenetic programming of differential gene-expression in development and evolution. Developmental Genetics, 17, 188-197. doi:10.1002/dvg.1020170303

[33] Feil, R. and Kelsey, G. (1997) Genomic imprinting: A chromatin connection. American Journal of Human Genetics, 61, 1213-1219. doi:10.1086/301655

[34] Barbacid, M. (1987) Ras genes. Annual Review of Biochemistry, 56, 779-827. doi:10.1146/annurev.bi.56.070187.004023

[35] Jones, P.A. and Laird, P.W. (1999) Cancer epigenetics comes of age. Nature Genet, 21, 163-167. doi:10.1038/5947

[36] Grady, W.M., Willis, J., Guilford, P.J., et al. (2000) Methylation of the CDH1 promoter as the second genetic hit in hereditary diffuse gastric cancer. Nature Genet, 26, 16-17. doi: $10.1038 / 79120$

[37] Baylin, S.B. and Herman J.G. (2000) DNA hypermethylation in tumorigenesis: Epigenetics joins genetics. Trends in Genetics, 16, 168-174. doi:10.1016/S0168-9525(99)01971-X

[38] Herman, J.G., Merlo, A. Mao, L., et al. (1995) Inactivation of the Cdkn2/P16/Mts1 gene is frequently associated with aberrant DNA methylation in all common human cancers. Cancer Research, 55, 4525-4530.

[39] Toyota, M., Ahuja, N., Ohe-Toyota, M., et al. (1999) CpG island methylator phenotype in colorectal cancer. Proceedings of the National Academy of Sciences of the United States of America, 96, 8681-8686. doi:10.1073/pnas.96.15.8681

[40] Toyota, M., Ho, C., Ahuja, N., et al. (1999) Identification of differentially methylated sequences in colorectal cancer by methylated CpG island amplification. Cancer Research, 59, 2307-2312.

[41] Ivanovich, J.L., Read, T.E., Ciske, D.J., et al. (1999) A practical approach to familial and hereditary colorectal cancer. American Journal of Medicine, 107, 68-77. doi:10.1016/S0002-9343(99)00168-0

[42] Watson, P. and Lynch, H.T. (1994) The Tumor Spectrum in Hnpcc. Anticancer Research, 14, 1635-1639.

[43] Aarnio, M., Sankila, R., Pukkala, E., et al. (1999) Cancer risk in mutation carriers of DNA-mismatch-repair genes. International Journal of Cancer, 81, 214-218. doi:10.1002/(SICI)1097-0215(19990412)81:2<214::AIDIJC8>3.0.CO;2-L
[44] Smyrk, T.C., Watson, P., Kaul, K., et al. (2001) Tumor-infiltrating lymphocytes are a marker for microsatellite instability in colorectal carcinoma. Cancer, 91, 24172422.

doi:10.1002/1097-0142(20010615)91:12<2417::AID-CN CR1276>3.0.CO;2-U

[45] Alexander, J., Watanabe, T., Wu, T.T., et al. (2001) Histopathological identification of colon cancer with microsatellite instability. American Journal of Pathology, 158, 527-535. doi:10.1016/S0002-9440(10)63994-6

[46] Jass, J.R., Young, J. and Leggett, B.A. (2002) Evolution of colorectal cancer: Change of pace and change of direction. Journal of Gastroenterology and Hepatology, 17, 17-26. doi:10.1046/j.1440-1746.2002.02635.x

[47] Galiatsatos, P. and Foulkes, W.D. (2006) Familial adenomatous polyposis. American Journal of Gastroenterology, 101, 385-398. doi:10.1111/j.1572-0241.2006.00375.x

[48] Talbot, I.C., Burt, R., Jarvinen, H., et al. (2000) Familial adenomatous polyposis. In: Hamilton, S.R. and Aaltonen, L.A., Eds., WHO Classification of Tumours, Pathology and Genetics of Tumours of the Digestive System. IARC Press, Lyon, 120-125.

[49] Fallen, T., Wilson, M., Morlan, B., et al. (2006) Desmoid tumors-A characterization of patients seen at Mayo Clinic 1976-1999. Familial Cancer, 5, 191-194. doi:10.1007/s10689-005-5959-5

[50] Tomoda, C., Miyauchi, A., Uruno, T., et al. (2004) Cribriform-morular variant of papillary thyroid carcinoma: Clue to early detection of familial adenomatous polyposis-associated colon cancer. World Journal of Surgery, 28, 886-889. doi:10.1007/s00268-004-7475-4

[51] Cetta, F., Montalto, G., Gori, M., et al. (2000) Germline mutations of the $A P C$ gene in patients with familial adenomatous polyposis-associated thyroid carcinoma: Results from a European cooperative study. Journal of Clinical Endocrinology \& Metabolism, 85, 286-292. doi:10.1210/jc.85.1.286

[52] Aretz, S., Koch, A., Uhlhaas, S., et al. (2006) Should children at risk for familial adenomatous polyposis be screened for hepatoblastoma and children with apparently sporadic hepatoblastoma be screened for $A P C$ germline mutations? Pediatric Blood \& Cancer, 47, 811-818. doi:10.1002/pbc.20698

[53] Munitz, M.I. (1986) Polyposis syndromes. In: Ott, D.J. and Wu, W.C., Eds., Polypoid Diseases of the Colon, Urban \& Schwarzenberg, Baltimore, 43-61.

[54] Dachman, A.H., Buck, J.L., Burke, A.P., et al. (1989) Cronkhite-Canada syndrome: Radiologic features. Gastrointestinal Radiology, 14, 285-290. doi:10.1007/BF01889219

[55] Gorlin, R.J., Cohen, M.M., Condon, L.M., et al. (1992) Bannayan-Riley-Ruvalcaba syndrome. American Journal of Medical Genetics, 44, 307-314. doi:10.1002/ajmg.1320440309

[56] Salem, O.S. and Steck, W.D. (1983) Cowdens disease (multiple hamartoma and neoplasia syndrome). A casereport and review of the English-literature. Journal of the 
American Academy of Dermatology, 8, 686-696. doi:10.1016/S0190-9622(83)70081-2

[57] Peutz, J.L.A. (1921) Over een zeer merkwaardige, gecombineerde familiaire polyposis van de slijmvliezen van den tractus intestinalis met die van de neuskeelholte en gepaard met eigenaardige pigmentaties van huiden slijmvliezen. Ned Maandschr v Geneesk, 10, 134-146.

[58] Jeghers, H., McKusick, V.A. and Katz, K.H. (1949) Generalized intestinal polyposis and melanin spots of the oral mucosa, lips and digits-A syndrome of diagnostic significance. New England Journal of Medicine, 241, 9931005. doi:10.1056/NEJM194912222412501

[59] Tomlinson, I.P.M. and Houlston, R.S. (1997) PeutzJeghers syndrome. Journal of Medical Genetics, 34, 1007-1011. doi:10.1136/jmg.34.12.1007

[60] Buck, J.L., Harned, R.K., Lichtenstein, J.E., et al. (1992) Peutz-Jeghers syndrome. Radiographics, 12, 365-378.

[61] Spigelman, A.D. and Phillips, R.K.S. (1994) Peutz-Jeghers syndrome. In: Phillips, R.K.S., Spigelman, A.D. and Thomson, J.P.S., Eds., Familial Adenomatous Polyposis and Other Polyposis Syndromes, Edward Arnold, London, 188-202.

[62] Wang, Z.J., Ellis, I., Zauber, P., et al. (1999) Allelic imbalance at the LKB1 (STK11) locus in tumours from patients with Peutz-Jeghers' syndrome provides evidence for a hamartoma-(adenoma)-carcinoma sequence. Journal of Pathology, 188, 9-13.

doi:10.1002/(SICI)1096-9896(199905)188:1<9::AID-PA TH326>3.0.CO;2-E

[63] Aaltonen, L.A. (2000) Hereditary intestinal cancer. Seminars in Cancer Biology, 10, 289-298. doi:10.1006/scbi.2000.0148

[64] McColl, I., Bussey, H.J.R., Veale, A.M.O., et al. (1964) Juvenile polyposis coli. Proceedings of the Royal Society of Medicine-London, 57, 896-897.

[65] Houlston, R., Bevan, S., Williams, A., et al. (1998) Mutations in DPC4 (SMAD4) cause juvenile polyposis syndrome, but only account for a minority of cases. Human Molecular Genetics, 7, 1907-1912. doi:10.1093/hmg/7.12.1907

[66] Howe, J.R., Bair, J.L., Sayed, M.G., et al. (2001) Germline mutations of the gene encoding bone morphogenetic protein receptor 1A in juvenile polyposis. Nature Genet, 28, 184-187. doi:10.1038/88919

[67] Sayed, M.G., Ahmed, A.F. Ringold, J.R. et al. (2002) Germline SMAD4 or BMPR1A mutations and phenotype of juvenile polyposis. Annals of Surgical Oncology, 9, 901-906. doi:10.1007/BF02557528

[68] Popat, S. and Houlston, R.S. (2005) A systematic review and meta-analysis of the relationship between chromosome 18q genotype, DCC status and colorectal cancer prognosis. European Journal of Cancer, 41, 2060-2070. doi:10.1016/j.ejca.2005.04.039

[69] Boland, C.R., Thibodeau, S.N. Hamilton, S.R., et al. (1998) A national cancer institute workshop on microsatellite instability for cancer detection and familial predisposition: Development of international criteria for the determination of microsatellite instability in colorectal cancer. Cancer Research, 58, 5248-5257.

[70] Huang, J., Papadopoulos, N., McKinley, A.J., et al. (1996) $A P C$ mutations in colorectal tumors with mismatch repair deficiency. Proceedings of the National Academy of Sciences of the United States of America, 93, 9049-9054. doi:10.1073/pnas.93.17.9049

[71] Konishi, M., Kikuchi-Yanoshita, R., Tanaka, K., et al. (1996) Molecular nature of colon tumors in hereditary nonpolyposis colon cancer, familial polyposis, and sporadic colon cancer. Gastroenterology, 111, 307-317. doi:10.1053/gast.1996.v111.pm8690195

[72] Miyaki, M., Iijima, T., Kimura, J., et al. (1999) Frequent mutation of ss-catenin and $A P C$ genes in primary colorectal tumors from patients with hereditary nonpolyposis colorectal cancer. Cancer Research, 59, 4506-4509.

[73] Fujiwara, T., Stolker, J.M., Watanabe, T., et al. (1998) Accumulated clonal genetic alterations in familial and sporadic colorectal carcinomas with widespread instability in microsatellite sequences. American Journal of Pathology, 153, 1063-1078. doi:10.1016/S0002-9440(10)65651-9

[74] Eshleman, J.R., Casey, G., Kochera, M.E., et al. (1998) Chromosome number and structure both are markedly stable in RER colorectal cancers and are not destabilized by mutation of $p 53$. Oncogene, 17, 719-725. doi:10.1038/sj.onc.1201986

[75] Yamamoto, H., Sawai, H. and Perucho M. (1997) Frameshift somatic mutations in gastrointestinal cancer of the microsatellite mutator phenotype. Cancer Research, 57, 4420-4426.

[76] Perucho, M. (1996) Cancer of the microsatellite mutator phenotype. Biological Chemistry, 377, 675-684.

[77] Yamamoto, H., Sawai, H., Weber, T.K. et al. (1998) Somatic frameshift mutations in DNA mismatch repair and proapoptosis genes in hereditary nonpolyposis colorectal cancer. Cancer Research, 58, 997-1003.

[78] Markowitz, S., Wang, J., Myeroff, L., et al. (1995) Inactivation of the type-II TGF-Beta receptor in colon-cancer cells with microsatellite instability. Science, 268, 13361338. doi:10.1126/science. 7761852

[79] Piao, Z., Fang, W., Malkhosyan, S., et al. (2000) Frequent frameshift mutations of RIZ in sporadic gastrointestinal and endometrial carcinomas with microsatellite instability. Cancer Research, 60, 4701-4704.

[80] Mori, Y., Yin, J., Rashid, A., et al. (2001) Instabilotyping: Comprehensive identification of frameshift mutations caused by coding region microsatellite instability. Cancer Research, 61, 6046-6049.

[81] Vasen, H.F.A., Watson, P., Mecklin, J.P., et al. (1999) New clinical criteria for hereditary nonpolyposis colorectal cancer (HNPCC, Lynch syndrome) proposed by the international collaborative group on HNPCC. Gastroenterology, 116, 1453-1456. doi:10.1016/S0016-5085(99)70510-X

[82] Vasen, H.F.A., Mecklin, J.P., Khan, P.M., et al. (1991) The international collaborative group on hereditary nonpolyposis colorectal cancer (ICG-HNPCC). Diseases of the Colon \& Rectum, 34, 424-425. 


\section{doi:10.1007/BF02053699}

[83] Rodriguez Bigas, M.A., Boland, C.R., Hamilton, S.R., et al. (1997) A National Cancer Institute workshop on hereditary nonpolyposis colorectal cancer syndrome: Meeting highlights and Bethesda guidelines. Journal of the National Cancer Institute, 89, 1758-1762.

[84] Umar, A., Boland, C.R., Terdiman, J.P., et al. (2004) Revised bethesda guidelines for hereditary nonpolyposis colorectal cancer (Lynch syndrome) and microsatellite instability. Journal of the National Cancer Institute, 96, 261-268. doi:10.1093/jnci/djh034

[85] Aaltonen, L.A., Salovaara, R., Kristo, P., et al. (1998) Incidence of hereditary nonpolyposis colorectal cancer and the feasibility of molecular screening for the disease. New England Journal of Medicine, 338, 1481-1487. doi:10.1056/NEJM199805213382101

[86] Lynch, H.T. and de la Chapelle, A. (2003) Genomic medicine-Hereditary colorectal cancer. New England Journal of Medicine, 348, 919-932. doi:10.1056/NEJMra012242

[87] Gryfe, R., Kim, H. Hsieh, E.T.K., et al. (2000) Tumor microsatellite instability and clinical outcome in young patients with colorectal cancer. New England Journal of Medicine, 342, 69-77.

\section{doi:10.1056/NEJM200001133420201}

[88] Popat, S., Hubner, R. and Houlston, R.S. (2005) Systematic review of microsatellite instability and colorectal cancer prognosis. Journal of Clinical Oncology, 23, 609-618. doi:10.1200/JCO.2005.01.086

[89] Lanza, G., Gafa, R., Santini, A., et al. (2006) Immunohistochemical test for MLH1 and MSH2 expression predicts clinical outcome in stage II and III colorectal cancer patients. Journal of Clinical Oncology, 24, 2359-2367. doi;10.1200/JCO.2005.03.2433

[90] Carethers, J.M., Smith, E.J., Behling, C.A., et al. (2004) Use of 5-fluorouracil and survival in patients with microsatellite-unstable colorectal cancer. Gastroenterology, 126, 394-401. doi:10.1053/j.gastro.2003.12.023

[91] Arnold, C.N., Goel, A. and Boland, C.R. (2003) Role of hMLH1 promoter hypermethylation in drug resistance to 5-fluorouracil in colorectal cancer cell lines. International Journal of Cancer, 106, 66-73. doi:10.1002/ijc.11176

[92] Ribic, C.M., Sargent, D.J., Moore, M.J., et al. (2003) Tumor microsatellite-instability status as a predictor of benefit from fluorouracil-based adjuvant chemotherapy for colon cancer. New England Journal of Medicine, 349, 247-257. doi:10.1056/NEJMoa022289 